\title{
The effect of vaginal progesterone suppository on prevention of preterm delivery
}

\author{
Lalooha $\mathrm{F}^{1}$, Movahed $\mathrm{F}^{2}$, Chegini $\mathrm{V}^{3}$, Pakniat $\mathbf{H}^{3}$, Takaloo $\mathrm{F}^{4}$ \\ 1. Associate Professor of Obstetrics and Gynecology, Department of Obstetrics and Gynecology, Faculty of Medicine, \\ Qazvin University of Medical Sciences, Qazvin, Iran. \\ 2. Associate Professor of Obstetrics and Gynecology, Department of Obstetrics and Gynecology, Faculty of Medicine, \\ Qazvin University of Medical Sciences, Qazvin, Iran (Corresponding Author), Tel: +98-2833236380, Email: \\ drmovahed@yahoo.com \\ 3. Assistant Professor of Obstetrics and Gynecology, Department of Obstetrics and Gynecology, Faculty of Medicine, \\ Qazvin University of Medical Sciences, Qazvin, Iran. \\ 4. Specialist of Obstetrics and Gynecology, Department of Obstetrics and Gynecology, Faculty of Medicine, Qazvin \\ University of Medical Sciences, Qazvin, Iran.
}

\begin{abstract}
Background and Aim: Preterm labor (PTL) is considered as one of the main causes of fetal mortality worldwide. Therefore, prevention of PTL is one of the main goals of midwifery care. The present study was conducted to determine the effect of vaginal progesterone suppository on the prevention of PTL.

Materials and Method: In this randomized clinical trial, 200 singleton pregnant women at 24 -34 weeks of gestation with diagnosis of PTL were treated with IV magnesium sulfate and corticosteroid. In the intervention group $(n=100)$, in addition to the above mentioned drugs, progesterone suppository $(200 \mathrm{mg})$ was administered at the start of treatment and every 12 hours until discontinuation of uterine contractions. After successful tocolysis, use of progesterone suppository continued until the end of the $34^{\text {th }}$ week.Midwifery outcome including the interval between the onset of tocolysis and discontinuation of uterine contractions and the occurrence of labor, the gestational age at the time of delivery and neonatal outcome were recorded in the two groups.

Results: The mean intervals between the start of tocolysis and discontinuation of uterine contractions were $6.33 \pm 3.78$ and $6.72 \pm 3.07$ hours $(\mathrm{p}=0.432)$ in the control and intervention groups respectively. Also, the intervals between successful tocolysis and delivery were $35.1 \pm 21.9$ and $36.7 \pm 25.1$ days respectively $(p=0.634)$. There was no significant difference between the two groups in terms of gestational age at the time of delivery and neonatal outcome. Although neonatal mortality in the control group was twice that in the intervention group, the difference was not significant $(\mathrm{p}=0.194)$.

Conclusion: The present study showed that vaginal progesterone suppository had no effect on the prevention of PTL.
\end{abstract}

Keywords: Progesterone, Vaginal Suppository, Preterm Labor, Gestational Age

Received: Jan 19, 2019

Accepted: Apr 24, 2019 


\section{تأثير شياف يروزسترون وازينال در ييشكيرى از زايمان زودرس}

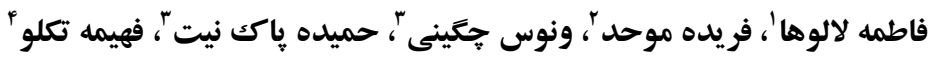

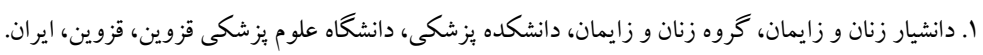

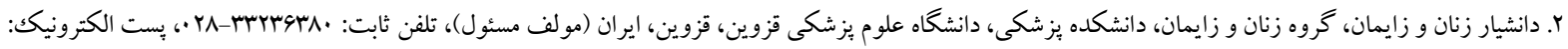
drmovahed@yahoo.com

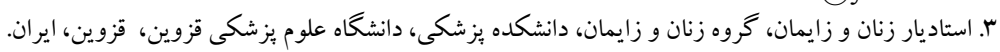

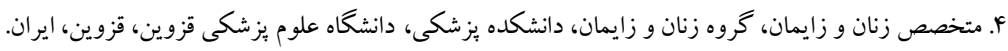

زمينه و هدف: زايمان بيش از موعد از علل اصلى مركُومير نوزادى در سطح جهان محسوب مىشود، لذا ييشيرى از زايمان

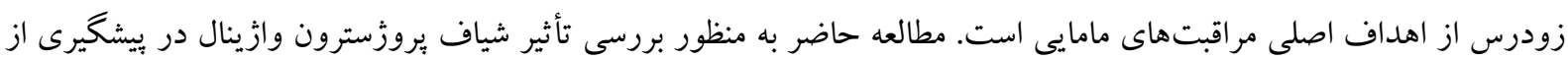

$$
\text { زايمان زودرس انجام شد. }
$$

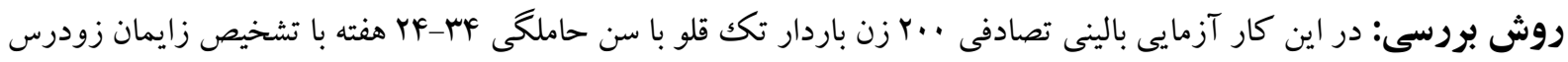

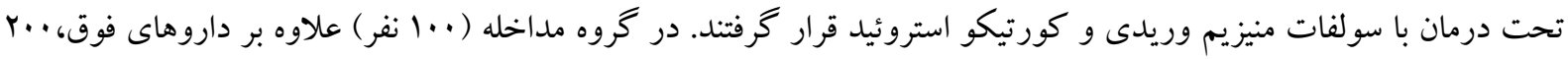

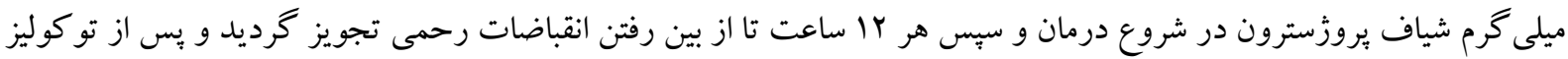

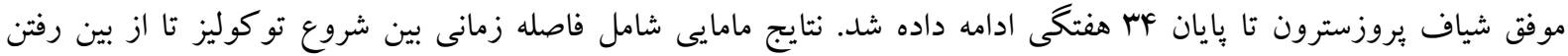

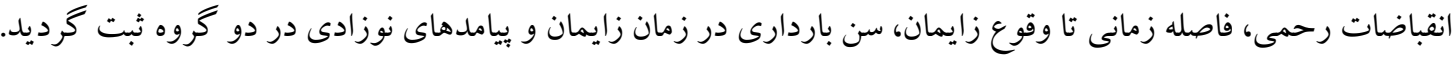

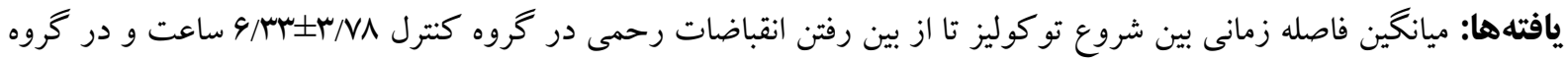
مداخله نشا

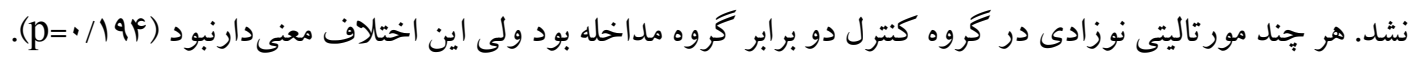

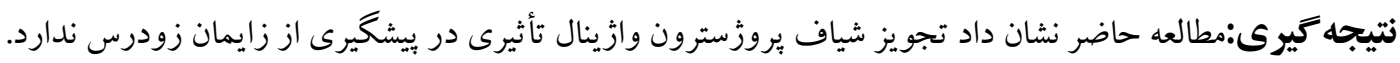

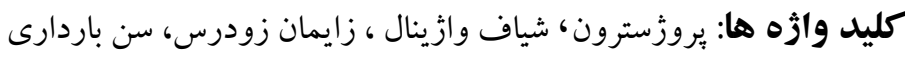

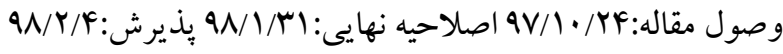


يرده هاى جنينى، مانع ازيارگى زودرس بردهها مىشودكه خود عامل شايع زايمان بره ترم است.

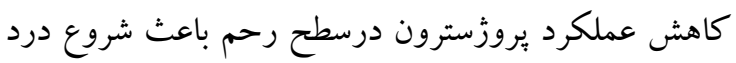

زايمان در حاملكى ترم و بره ترم مى شود (11).

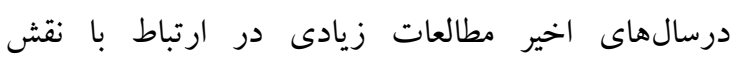

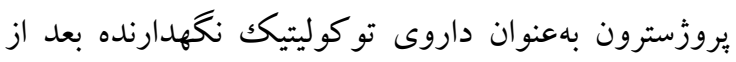
توقف موفقيت آميز زايمان زودرس انجام شده ولى نتايج مطالعات با هم در تناقض است. يكك مطالعه مرور

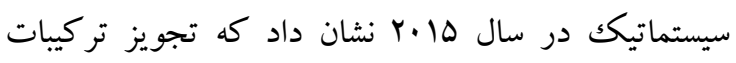

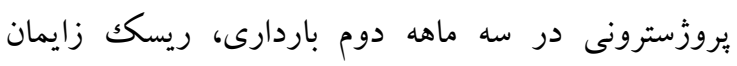

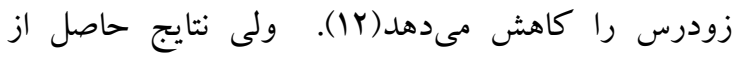
جندين كار آزمايى بالينى تصادفى نتوانست اثر مثبت استفاده

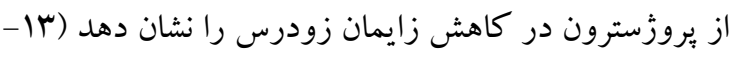

لذا به نظر مىرسد براى اثبات اثربخشى يروزسترون در توقف زايمان زودرس نياز به انجام مطالعات بيشتر باشد.باتوجه به اينكه زايمان زودرس با مورتاليتى ليان وموربيديتى نوزادى و هزينههاى اجتماعى و اقتصادى بالايى همراه است، بر آن شديم كه تأثيرشياف بروزّترون وازينال

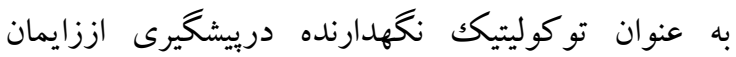
زودرس را مورد بررسى قرار دهيم.

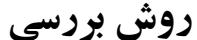

اين مطالعه به صورت كار آزمايى بالينى تصادفى پس ازتائيد

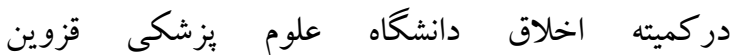
(IR.QUMS.REC.1394.2000) IRCT2016112331046N1 آزمايى بالينى ايران درمركز آموزشى درمانى كوثر قزوين در سال هوسا انجام

حجم نمونه اين مطالعه با درنظر گرفتن سطح اطمينان (هD٪)

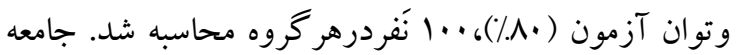
مورد مطالعه تمام زنان باردارتكك قلو FF-MF هفته (سن دقيق

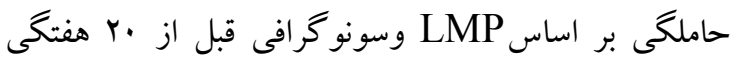

زايمان زودرس به تولد نوزاد قبل از كامل شدن TV هفته باردارى كفته مىشود(1). زايمان زودرس در طى دهاهاى اخير افزايش ييداكرده است و از علل اصلى مركگومير

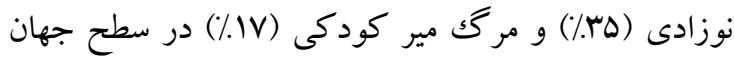
است (Y). نوزاد نارس در معرض عوارض كو تاه مدت مانند نارسايى جند اركان و عوارض درازمدت شامل ناتوانىهاى

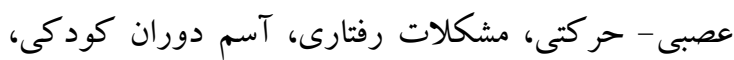

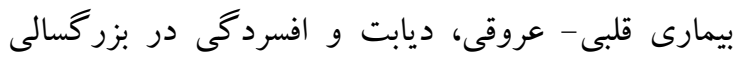
است. علاوه بر اين زايمان زودرس همراه با هزينه هاى بالاى بلى اجتماعى و اثر منفى روانى بر افراد خانو اده همراه است (r).

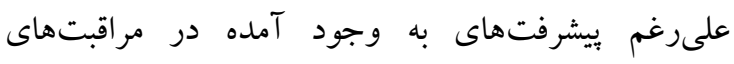
نوزادى، زايمان زودرس همجنان علت اصلى ناتوانى در بهر كودكان بدون ناهنجارىهاى مادرزادى است(א). بنابراين رودئ

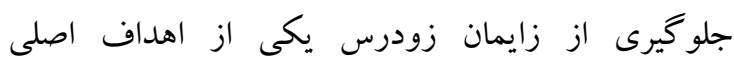
مر اقبت هاى مامايى است (ه).

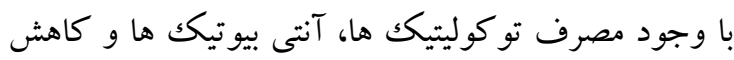
فعاليتهاى جسمانى مادر باردار، هنوز روش قطعى در

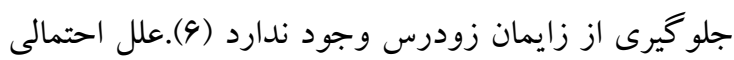
مطرحشده در زايمان زودرس شامل سابقه قبلى، طول

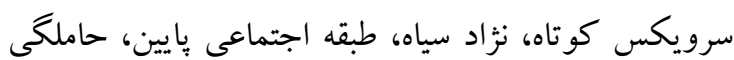
جند قلويى، سن مادر (دو طيف بالا و يايين)، مصرف سيكار

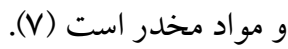
يروزسترون هورمون استروئيدى است كه توسط كوريوس

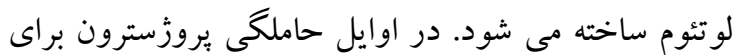

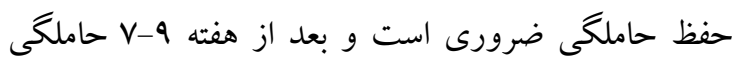

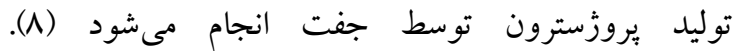
يروزسترون در حفظ آرامش رحم در نيمه دوم حاملكى توسئ نقش مهمى دارد(9). اكر جه مكانيسم اثر توكوليتيك

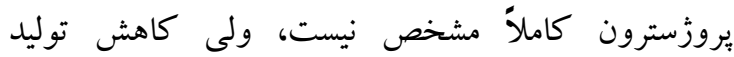
يروستاكلاندين ها و همجنين جلو گيرى از فعاليت

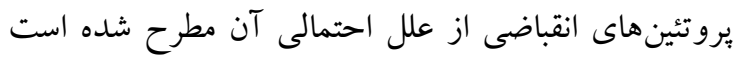
(.). از طرف ديخر بروزسترون با جلو گيرى ازآيويتوز 
نوزادى دردو گروه ثبت گرديد.كليه اطلاعات بيماران وارد نرم افزارSPSS شده و آناليز هاى آمارى در دود دود بخش درد

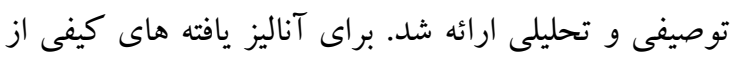
آزمون كاى اسكوير و براى مقايسه دادههاى كمى از آزمون

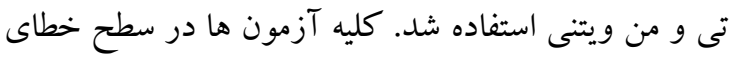

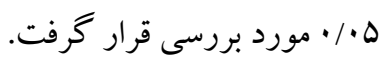

يافتهها

مشخصات دمو گرافيك شامل سن مادر، تعداد باردارى، تعداد زايمان، سابقه زايمان زودرس در جدول شماره آورده شده است. ميانگين و انحراف معيار سن حاملكى در

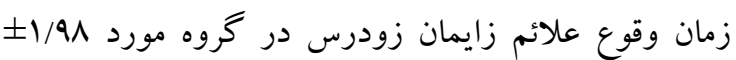

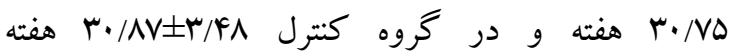

$$
\text { بود }
$$

ميانگين و انحراف معيار فاصله زمانى بين شروع تو كوليز تا

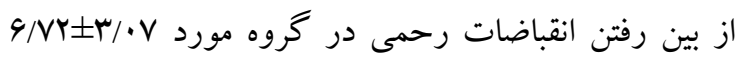

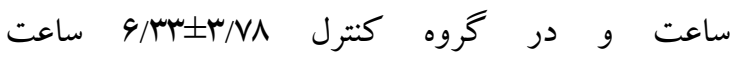

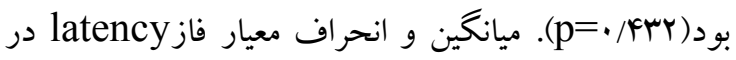
گروه مورد ه  باردارى در هنگام زايمان در گروه مورد

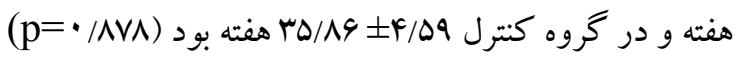

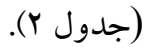

ساير متغيرهاى مورد مطالعه شامل نمره آيگار، وزن نوزاد و مدت زمان بسترى نوزاد در NICU و نيز بيامد هاى نوزادى به تفكيك دو گروه در جدول شماره ب آورده شده است.

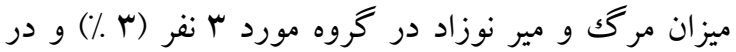

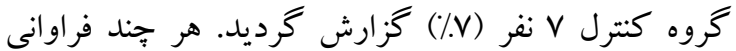
مركَ و مير در گروه كنترل دو برابر گروه مورد بود اما اين

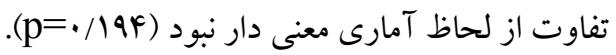

تائيد شده بود) باعلائم زايمان زودرس (وجود حداقل F انقباض و يا بيشتر طى •ا دقيقه كه با توكوديامتر ثبت

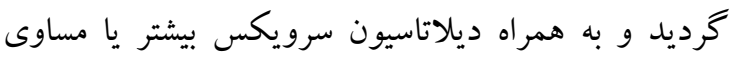
اسانتى متر) مراجعه كننده به بيمارستان كوثر قزوين بودند.

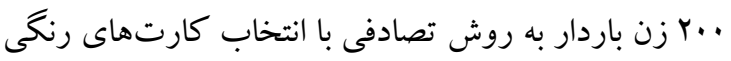

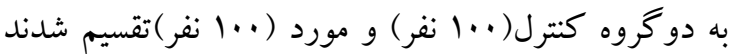
كه پِ از تكميل فرم رضايتنامه آكاهانه وارد مطالعه

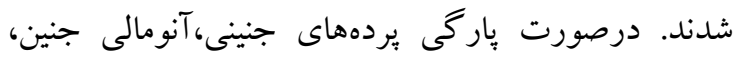

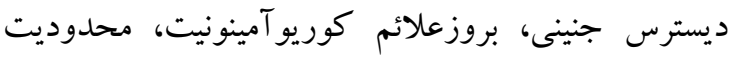
رشد جنينى و وجودبيمارىهاى زمينهاى مانند يرفشارى خون از مطالعه خارج شدند. در ابتدا مشخصات دمو گرافيك شامل سن، تعداد باردارى، تعداد زايمان، سن باردارى، سابقه زايمان زودرس ثبت

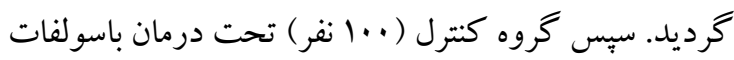

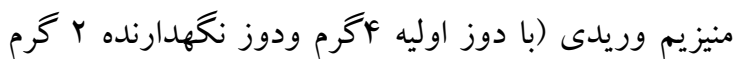
درساعت براى YF ساعت) و Fلو كو كورتيكوئيد (Y دوز

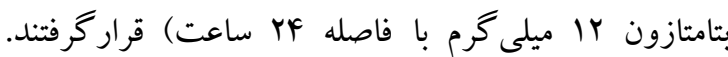

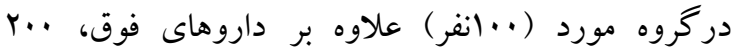

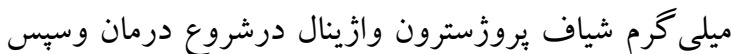
هر rا ساعت تا از بين رفتن انقباضات رحمى تجويزشد. بِ ازتوكوليزموفقيت آميز(يكك دوره وجودانقباضات رحمى بعد از اتمام توكوليز وريدى) روزانه

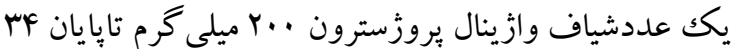

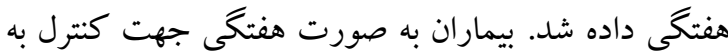
درمانگاه بره ناتال مراجعه كردند. نتايج مامايى شامل فاصله

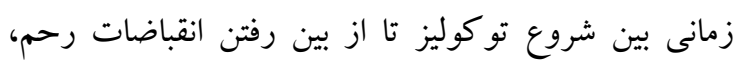

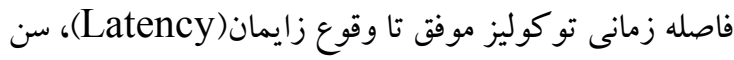
باردارى در زمان زايمان و نيز بيامدهاى نوزادى شامل آيخار

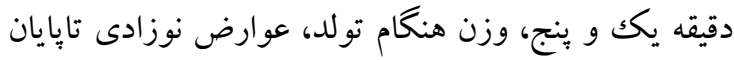
N روزگى، مدت زمان بسترى نوزاددر NICU ومرگك 


\begin{tabular}{|c|c|c|c|}
\hline \multirow{2}{*}{ P-value } & كنترل & 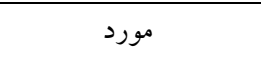 & \multirow[b]{2}{*}{ متغير } \\
\hline & انحر اف معيار土 ميانخين & انحر اف معيار土 ميانگين & \\
\hline$\cdot / 491$ & $r V / G F \pm \Delta / F V$ & 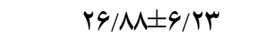 & سن مادر (سال) \\
\hline$\cdot / 190$ & $r \cdot / \Lambda V \pm r / F \Lambda$ & $r \cdot / v \Delta \pm 1 / 9 \Lambda$ & سن باردارى (هفته) \\
\hline $1 / \cdots$ & $r / 1 Y \pm 1 / 19$ & $r / / Y \pm I / I r$ & تعداد باردارى \\
\hline$\cdot / \Lambda 1 \Lambda$ & $\cdot / \vee Q \pm \cdot / \wedge q$ & $\cdot / \Lambda Y \pm \cdot / q F$ & تعداد زايمان \\
\hline.$/|r|$ & $\Lambda(/ / \wedge)$ & $\Gamma(/ / r)$ & سابقه زايمان زودرس (تعداد و درصد) \\
\hline
\end{tabular}

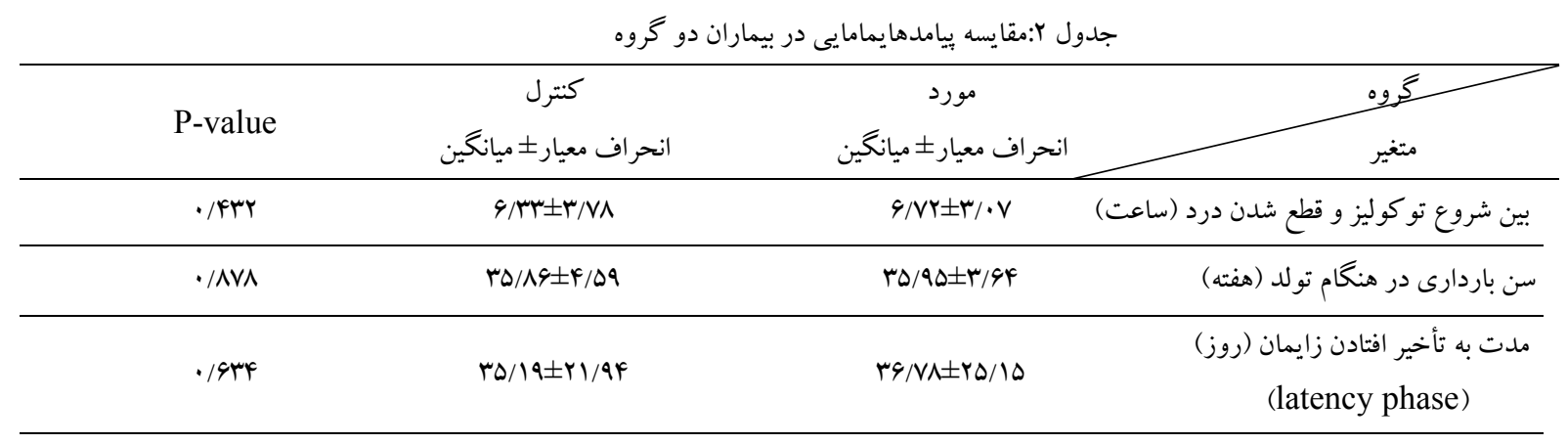

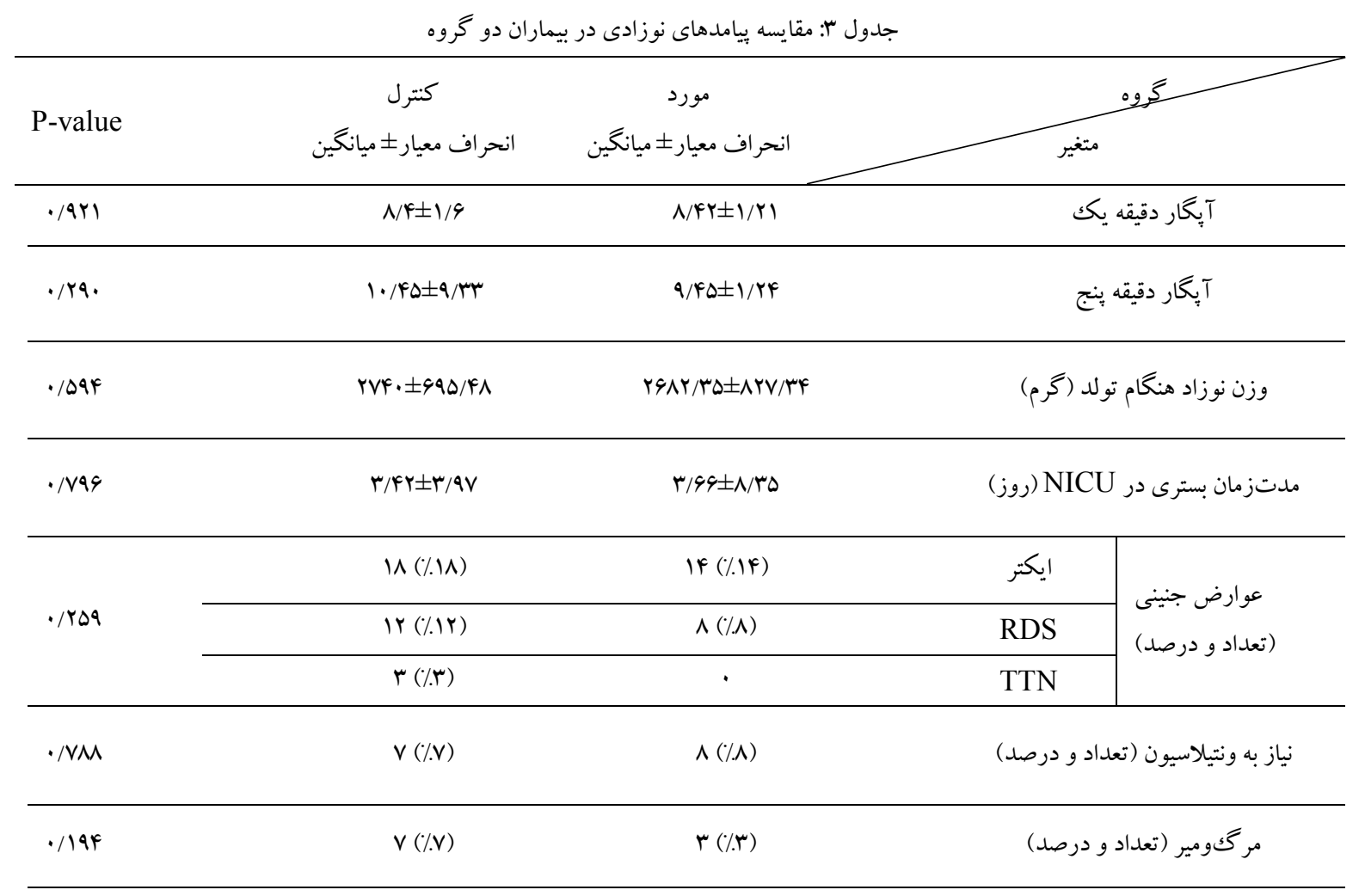


نمىدهد كه با مطالعه ما همسو بود.ولى زمان متوسط تا زايمان در گروه مداخله به طور معنىدارى افزايش يافت. (pe (p) در حالى كه در مطالعه ما اين زمان در دو گروه اختلاف معنىدارى نداشت. اين اختلاف مىتواند ناشى از ادامه مصرف بروزسترون تا سن حاملكى

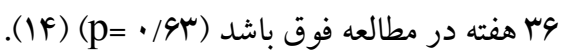
در مطالعه دو سو كور و جند مركزى كه توسط Norman

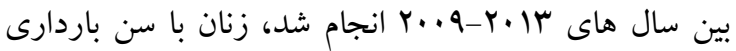
هe rF-MF ro إبقه زايمان زودرس قبلى، طول سرويكس كمتر از

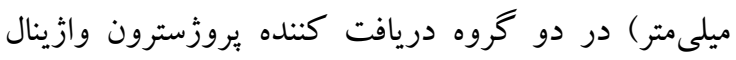
ميلى F... مطالعه نشان داد كه مصرف يروزسترون وازينال باعث

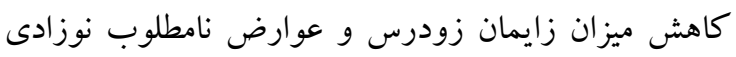
نمىشود. على رغم اينكه طراحى مطالعه فوق با مطالعه حاضر متفاوت بود و زنان باردار بدون علائم زايمان زودرس و تنها به علت داشتن فاكتورهاى خطر به صورت يروفيلاكسى :بروزسترون دريافت كردند ولى نتايج آن با با نتايج مطالعه ما همخو انى داشت (10). در مورد فرمو لاسيون، دوز، مدت مصرف و روش ايده آل مصرف يروزسترون هنوز هم اتفاق نظر وجود ندارد.

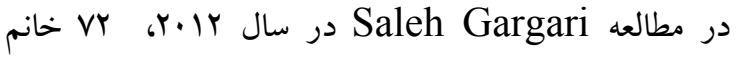
باردار مبتلا به بره ترم ليبر با سن باردارى FF-MF هفته، ابتدا

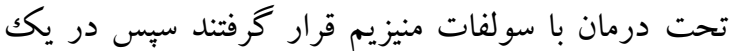

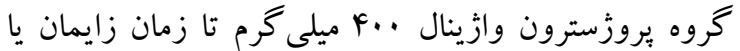

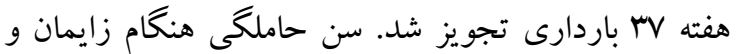
زمان Latency در گروه مداخله به صورت معنىدار بالاتر

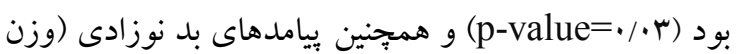
كم هنگام تولد و زمان بسترى در NICU) در گروه مداخله كاهش نشان داد كه با نتيجه مطالعه ما متفاوت بود. اين تفاوت مىتواندناشى از اختلاف در دوز مصرفى يروزسترون و نيز مدت مصرف آن باشد (19).
يافتهاى مطالعه حاضر نشان داد كه تجويز شياف يروزسترون وازينال به عنوان توكوليتيك نكهدارنده بعد از سر كوب انقباضات رحمى، در بيشخيرى از زايمان زودرس

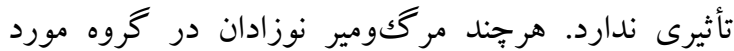
كمتر از گروه كنترل بود ولى اين تفاوت از لحاظ آمارى معنى دار نبود. تاكنون مطالعات زيادى در رابطه با مصرف يروزسترون به عنوان تو كوليتيك نخهدارنده در ييشخيرى از

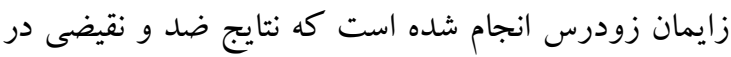

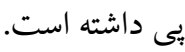
در يك كار آزمايى بالينى كه توسط Tejada در سال re

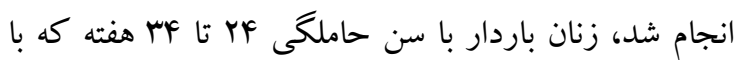
علائم زايمان زودرس مراجعه كرده بودند تحت توكوليز

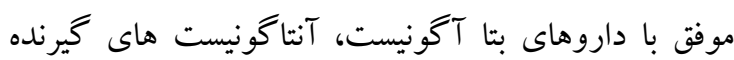
اكسى توسين يا مسدود كننده هاى كانال كلسيم قرار گر فتند

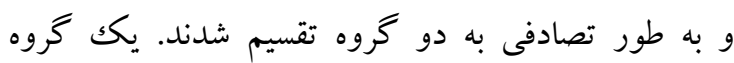

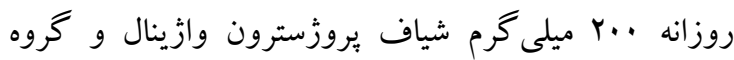

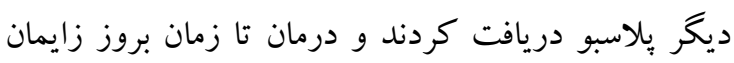

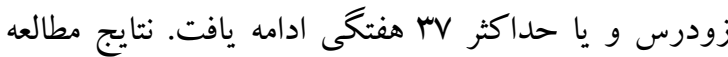
نشان داد كه مصرف شياف يروزسترون نتوانست ميزان زايمان زودرس و نيز يِيامدهاى يرى ناتال را بهبود بخشد.

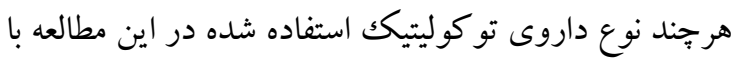
مطالعه ما متفاوت بود ولى نتايج حاصله از دو مطالعه با هم

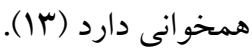
در مطالعه دوسو كور كه توسط Sharami در سال .1.1

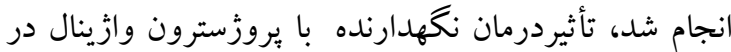
IVT زن با سن حاملكى YA-YA هفته كه با علائم زايمان زودرس مراجعه كرده بودند مورد بررسى قرار گرفت. در

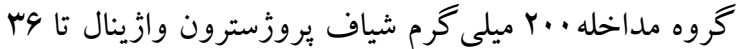
هفته و در گروه كنترل بِلاسبو داده شد و ميزان بروز زايمان

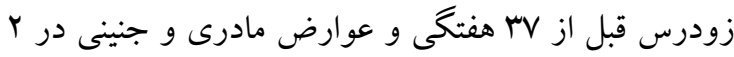

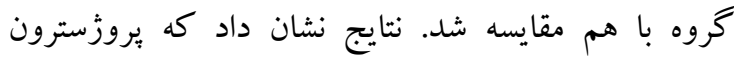
وازينال ميزان زايمان زودرس را قبل از هV هفته كاهش 
در نهايت به نظر مىرسد كه تناقض بين كارايى مصرف يروزسترون وازينال ممكن است به علت تفاوت در زمان بهان شروع مصرف يروزسترون، دوز مصرفى بروزسترون وازينال يا نحوه انتخاب نمونه و حجم نمونه باشد.

\section{نتيجه كيرى}

نتايج مطالعه نشان داد كه تجويز شياف بروزَسترون وازينال

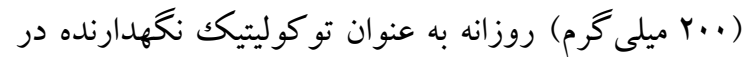

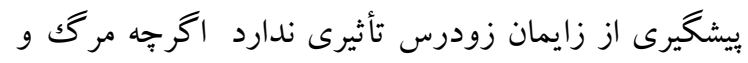

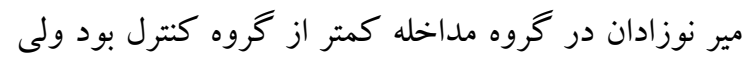

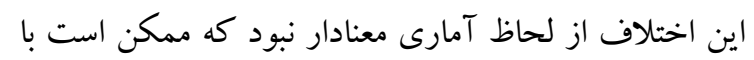
انجام مطالعه اى با حجم نمونه بالاتر و كنترل دقيق عوامل مخدوش كننده مثل شاخص هاى دمو گر افيك مادران باردار، سن باردارى و سابقه بيمارى در مادران سبب مشخص شدن

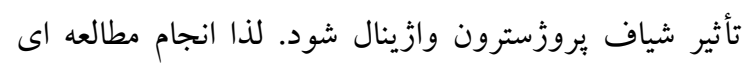
مشابه با حجم نمونه بالاتر بيشنهاد مىشود.

\section{تشكر و قدردانى}

اين ئزوهش بركرفته از بايان نامه دكترى تخصصى يز شكى

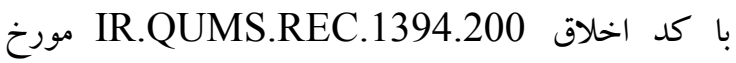
TF/N/IT مى باشد. بدين وسيله از همكارى مركز توسعه تحقيقات بالينى بيمارستان كوثر تشكر و قدردانى مى گردد.
در مطالعه انجام شده توسط Bomba درسال 1 •r، .19 خانم باردار با علائم زايمان زودرس تحت درمان با تحان

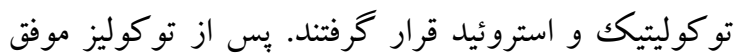

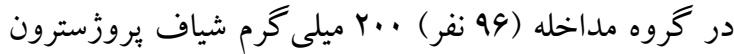

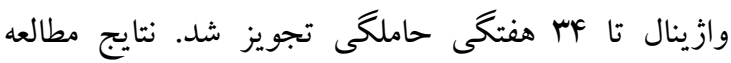

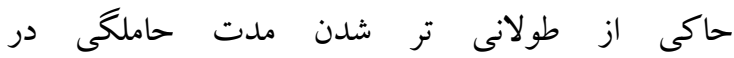

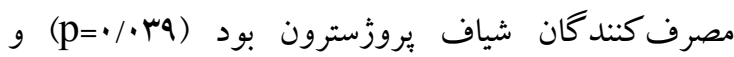
همجنين زايمان قبل از FF هفته به طور معنىدارى كاهش لرق

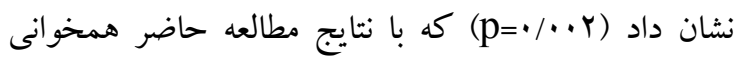

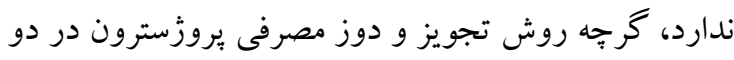

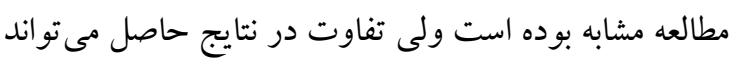
ناشى از ياسخدهى متفاوت گيرندههاى عضلات صاف رحم

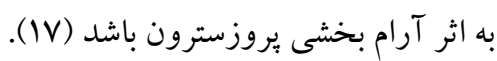

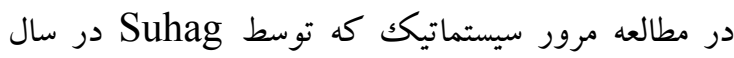

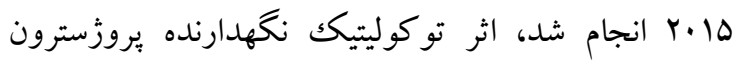

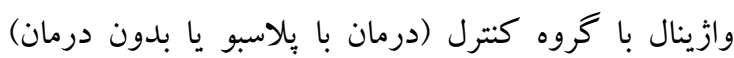
مقايسه شد. نتايج نشان داد كه ميزان زايمان زودرس (قبل از

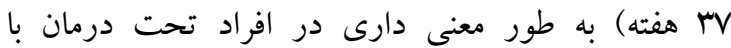
يروزسترون وازينال كمتر بود و مصرف توكوليتيك

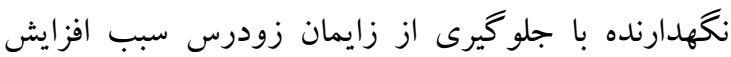

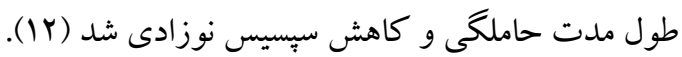

\section{References}

1. Gibb W, Challis JR: Mechanisms of term and preterm birth. J Obstet Gynaecl Can 2002;24: 874-82.

2. Goldenberg RL, Culhane JF, Iams JD, Romero R. Epidemiology andcauses of preterm birth. Lancet 2008;371:75-84.

3. Goldenberg RL, Andrews WW, Hauth JC. Choriodecidual infectionand preterm birth. Nutr Rev 2002;60:19-25.

4. Cunningham FG, Bloom SL, Leveno KJ, Bloom S, Spong C, Dashe J. Williams obstetrics. 23rd ed. New York: McGraw-Hill, 2014.

5. Loudon JA, Groom KM, Bennett PR. Prostaglandin inhibitors in preterm labour. Best Pract Res Clin Obstet Gynaecol 2003;17:731-44.

6. Rust OA, Bofill JA, Arriola RM,Andrew ME, Morrison JC. The clinical efficacy of oral tocolytictherapy. Am J Obstet Gynecol 1996;175:838-42. 
7. Thornton JG. Maintenance tocolysis. BJOG 2005;112:118-21.

8. Roberts D, Dalziel S. Antenatal corticosteroids for accelerating fetallung maturation for women at risk of preterm birth. Cochrane DatabaseSyst Rev 2006;3:44-54.

9. Gaunekar NN, Crowther CA. Maintenance therapy with calciumchannel blockers for preventing preterm birth after threatened pretermlabour. Cochrane Database Syst Rev 2004;3:CD004071.

10. Daya S, Gunby J. Luteal phase support in assisted reproduction cycles. Cochrane Database Syst Rev 2004;CD004830.

11. Mesiano S, Welsh TN. Steroid hormone control of myometrialcontractility and parturition. Semin Cell Dev Biol 2007;18:321-31.

12. Suhag A, Saccone G, Berghella V. Vaginal progesterone for maintenance tocolysis: a systematic review and metaanalysis of randomized trials. Am J Obstet Gyneco 2015;213:47987.

13. Martinez de Tejada B, Karolinski A, Ocampo MC, Laterra C, Hösli I, Fernández D, et al. Prevention of preterm delivery with vaginal progesterone in women with preterm labour (4P): randomised double blind placebo controlled trial. BJOG 2015;122:80-91.

14. Sharami SH, Zahiri Z, Shakiba M, Milani F. maintenance therapy by vaginal progesterone after threatened idiopathic preterm labor: a randomized placebo-controlled double-blind trial. Int J fertil steril 2010;4:45-50.

15. Norman JE, Marlow N, Messow CM, Shennan A, Bennett PR, Thornton S, et al. Vaginal progesterone prophylaxis for preterm birth (the OPPTIMUM study): a multicentre, randomised, double-blind trial. Lancet 2016;387:2106-16.

16. Saleh Gargari S, Habibolahi M, Zonobi Z, Khani Z, Sarfjoo FS, Kazemi Robati A, et al. Outcome of vaginal progesterone as a tocolytic agent: randomized clinical trial. ISRN Obstet Gynecol 2012;2012:23.

17. Bomba-Opon DA, Kosinska-Kaczynska K, Kosinski P, Wegrzyn P, Kaczynski B, Wielgos M. Vaginal progesterone after tocolytic therapy in threatened preterm labor. J Matern Fetal Neonatal Med 2012;25:1156-9. 